\title{
Analisis Respon Masyarakat Terhadap Kebijakan Aglomerasi Transportasi Massal Bus Rapid Transit (BRT) Di Kabupaten Semarang
}

\author{
Dias Fajar Priyanto ${ }^{凶}$ \\ Jurusan Ekonomi Pembangunan,Fakultas Ekonomi, Universitas Negeri Semarang \\ Permalink/DOI: https://doi.org/10.15294/efficient.vii3.27870 \\ Received: April 2018; Accepted: July 2018 ; Published: October 2018
}

\begin{abstract}
The background of this study aims to see the response of people in Semarang regency by the policy of mass transportation agglomeration Bus Rapid Transit (BRT). Data collected through literature study, questionnaires, direct observation and documentation. Data analysis technique is descriptive percentage. The results show some of the public response with public transportation angkot / bus 55\% community response still does not accelerate travel time. As many as $94 \%$ of people in Semarang Regency are very interested and much needed by the development of mass transportation based on Bus Rapid Transit (BRT). As many as 88\% of the people in Semarang district need cheap transportation, safe and convenient. The public prefers BRT mass transportation as opposed to using Private vehicles by $54 \%$. Most of them with $52 \%$ of people in Semarang regency do not know the route of BRT to be passed from Semarang (Tawang) - Semarang Regency (Bawen). Suggestion for Central Java government to carry out mass transit Bus Rapid Transit (BRT) connected with Semarang City which bertrayek in Semarang Regency (Bawen) - Semarang City (Tawang). The government also evaluates the location of shelters that feed on street users.
\end{abstract}

Keywords: Mass Transportation, Agglomeration, Bus Rapid Transit (BRT)

\begin{abstract}
Abstrak
Latar belakang penelitian ini bertujuan untuk melihat respon masyarakat di Kabupaten Semarang dengan adanya Kebijakan Aglomerasi transportasi massal Bus Rapid Transit (BRT). Data yang dikumpulkan melalui studi pustaka, kuesioner, observasi secara langsung dan dokumentasi. Teknik analisis data adalah deskriptif presentase. Hasil yang ditunjukan sebagian respon masyarakat dengan ada angkutan umum angkot/bus 55\% respon masyarakat masih tidak mempercepat waktu tempuh. Sebesar $94 \%$ masyarakat di Kabupaten Semarang sangat minat dan sangat dibutuhkan dengan adanya perkembangan transportasi massal berbasis Bus Rapid Transit (BRT). Sebanyak $88 \%$ masyarakat di kabupaten Semarang membutuhkan transportasi yang murah tarifnya, aman dan nyaman. Masyarakat lebih memilih transportasi massal BRT dibandingkan dengan menggunakan kendaraan Pribadi sebesar 54\%. Sebagian besar dengan sejumlah 52\% masyarakat di Kabupaten Semarang belum mengetahui rute BRT yang akan dilalui dari Semarang (Tawang) - Kabupaten Semarang (Bawen). Saran untuk pemerintah Jawa Tengah untuk melaksanakan transportasi massal Bus Rapid Transit (BRT) yang terhubung dengan Kota Semarang yang bertrayek di Kabupaten Semarang (Bawen) - Kota Semarang (Tawang). Pemerintah juga mengevaluasi letak shelter yang memakan hak pengguna jalan kaki.
\end{abstract}

\section{Kata Kunci: tranasportasi massal, agglomerasi, Bus Rapid Transit (BRT)}

How to Cite: Priyanto, D. (2018). Analisis Respon Masyarakat Terhadap Kebijakan Aglomerasi Transportasi Massal Bus Rapid Transit (Brt) Di Kabupaten Semarang. EFFICIENT Indonesian Journal of Development Economics, 1(3), 252-259. https://doi.org/10.15294/efficient.vii3.27870

(C) 2018 Semarang State University. All rights reserved

\footnotetext{
Alamat Korespondensi :

Alamat: Gedung L2 Lantai 2 FE Unnes

Kampus Sekaran, Gunungpati, Semarang, 50229

E-mail : Dias.fajar.bismania@gmail.com
}

ISSN 


\section{PENDAHULUAN}

Pada zaman yang berkembang pesat ini transportasi sangat dibutuhkan pada kehidupan seseorang dalam menjalankan aktivitasnya, apalagi ketika seseorang tersebut masyarakat kecil dan menengah supaya dapat melaksanakan kegiatannya sesuai dengan tugas dan fungsinya dalam masyarakat. Transportasi merupakan permasalahan yang mempunyai pengaruh penting dalam kehidupan masyarakat modern. Salah satu bagian dari transportasi yaitu transportasi darat. Kendaraan bermotor merupakan sarana yang mutlak diperlukan dalam transportasi darat. Jumlah pengguna kendaraan bermotor sekarang semakin meningkat dari tahun ke tahun. Hal ini menjadi indikasi bahwa masyarakat sekarang semakin membutuhkan sarana transportasi sejalan dengan bertambahnya jumlah penduduk. Maka dari itu seiring meningkatnya pertumbuhan peduduk di Indonesia yang sedang berkembang ini maka mode transportasi massal. Pengembangan angkutan umum massal berbasis jalan di wilayah perkotaan di Indonesia diarahkan untuk menciptakan pelayanan yang handal dan terjangkau oleh seluruh lapisan masyarakat pengguna jasa angkutan umum. Pada jangka panjang, diharapkan keberadaan pelayanan angkutan umum yang handal akan mampu mengurangi ketergantungan masyarakat terhadap penggunaan kendaraan pribadi.

Provinsi Jawa Tengah memiliki suatu peranan visi dan misi yang akan revilitasi, modernisasi dan pengembangan sarana dan prasarana transportasi dalam rangka pelayanan terintegrasi, berkelanjutan dan ramah lingkungan guna peningkatan aksebilitas dan mobilitas. Pemerintah Jawa
Tengah pada tahun ini akan mengembangkan sistem transportasi Aglomerasi, yakni sistem transportasi dengan pelayanan Bus Rapid Transit (BRT) yang tidak terbatas wilayah administratif, tapi bisa meliputi dua kabupaten atau lebih. Sistem tersebut di harapkan dapat mengurangi angka kecelakaan, kemacetan dan mengurangi jumlah kendaraan pribadi beralih ke transportasi massal Bus Rapid Transit (BRT).

Permasalahan dengan kondisi transportasi yang dipinggiran ibukota Jawa Tengah tersebut, Kabupaten Semarang memiliki letak yang strategis dan bersebelahan dengan Kota Semarang. Kabupaten Semarang menjadi salah satu bentuk kerjasama dalam kota/kabupaten yang membuat fungsi transportasi yang memiliki suatu peranan penting didalam pengembangan kawasan aglomerasi transportasi massal Bus Rapid Transit (BRT) di Jawa Tengah.

Pada gambar 1 menunjukkan bahwa dua angkutan umum, yaitu angkutan pedesaan dalam kota dan angkutan pedesaan. Pada gambar 1 menujukan bahwa grafik Angkutan pedesaan dalam kota pada tahun 2007 menggalami penurunan setiap tahunnya. Penurunan grafik suatu armada angkutan pedesaan dalam kota pada setiap tahunnya ini, disebabkan karena minat masyarakat yang mulai memiliki transportasi pribadi. Grafik diatas menjelaskan dari garis berwarna biru tersebut jenis armada angkutan umum pedesaan dalam 5 tahun tersebut, pada tahun 2012 merupakan tahun yang mengalami penurunan 438 armada Angkutan yang semula di tahun 2011 berjumlah 560 armada angkutan pedesaan dalam kota, hal ini juga di tunjukan pada angkutan pedesaan yang turun sejumlah 475 armada yang semula berjumlah 
546 armada di tahun 2010. Penurunan jumlah angkutan umum pada tahun 2012 disebabkan karena adanya trayek didahulukan oleh angkutan lain, puluhan angkutan pedesaan (Angkudes). Jawa Tengah sendiri kini telah ada suatu angkutan umum massal seperti halnya Bus Rapid Transit (BRT). Di Jawa Tengah yang sudah melakukan modernisasi angkutan seperti BRT tersebut didaerah Kota Semarang dan Solo saja. Pada kebijakan aglomerasi tersebut akan memberikan suatu modernisasi pada angkutan umum di Jawa Tengah, dengan adanya aglomerasi transportasi ini dapat memberikan suatu pengaruh terhadap perkembangan daerah-daerah yang terkena suatu lingkup adanya kebijakan aglomerasi.
Namun dengan adanya kebijakan aglomerasi ini akan berimbas pada kalangan angkutan umum lainnya, terutama dengan trayek (angkutan trayek) yang tentunya berhimpitan dengan adanya kebijakan aglomerasi transportasi tersebut.

Oleh sebab itu, dibutuhkan sebuah analisis mengenai suatu respon masyarakat terhadap kebijakan aglomerasi transportasi massal di daerah tersebut, untuk mengetahui masyarakat Kabupaten Semarang apakah merasa nyaman atau tidak dengan adanya angkutan massal (BRT) tersebut. Karena hal ini dapat mendorong suatu pengembangan di dunia transportasi yang lebih nyaman, aman, dan tentunya ramah.

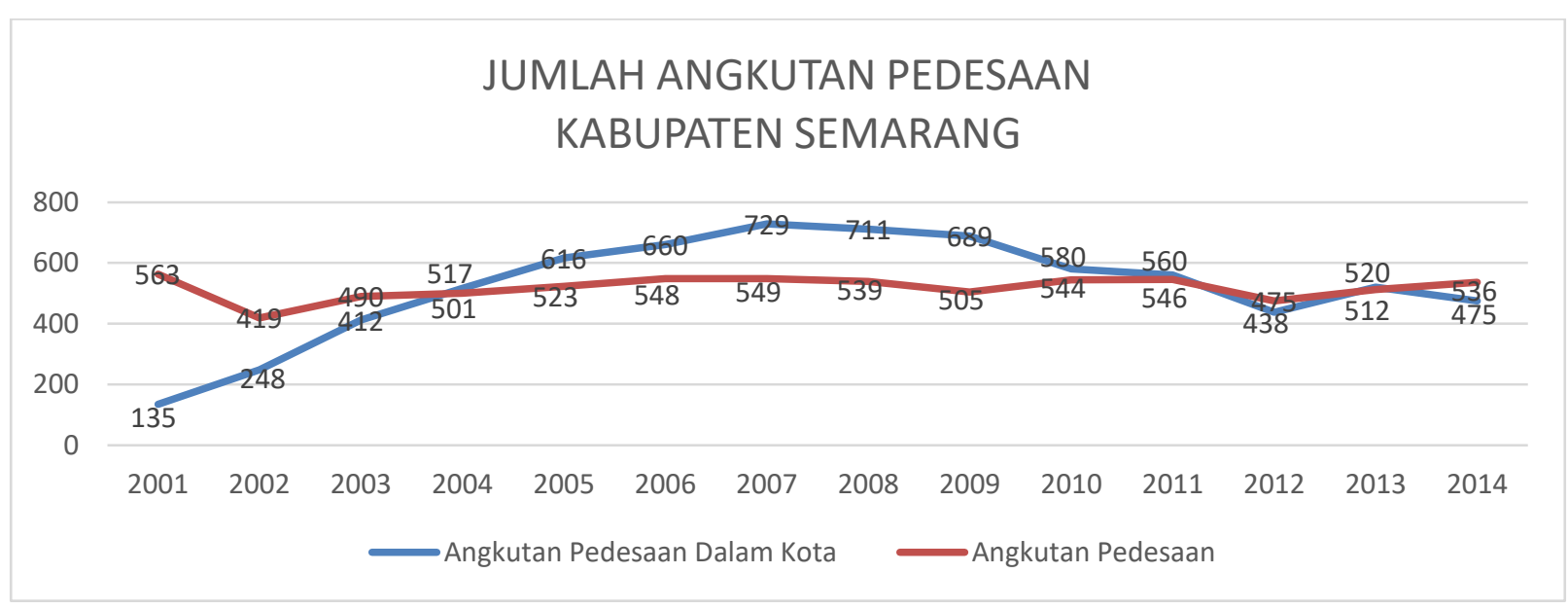

Gambar 1. Jumlah Angkutan Umum Pedesaan Dalam Kota dan Angkutan Umum Pedesaan Antar Kota. Sumber : BPS Kabupaten Semarang (Dinas Perhubungan)

\section{METODE PENELITIAN}

\section{Jenis Penelitian}

Penelitian ini menggunakan pendekatan kualitatif yaitu penelitian yang bermaksud untuk memahami fenomena tentang apa yang dialami oleh subjek penelitian secara holitistik dan dengan cara deskripsi dalam bentuk katakata dan bahasa, pada suatu konteks khusus yang alamiah dan dengan memanfaatkan berbagai metoe ilmiah Penelitian deskriptif kualitatif yang digunakan pada penelitian ini dimaksudkan untuk memperoleh informasi mengenai suatu bentuk 
respon masyarakat setempat di Kabupaten Semarang dengan adanaya program atau kebijakan aglomerasi transportasi massal berbasis Bus Rapid Transit (BRT).

\section{Jenis dan Sumber Data}

Jenis dan sumber data yang digunakan dalam penelitian ini adalah data kualitatif. Adapun jenis-jenis dengan sumber data yang digunakan dalam penelitian ini dibagi menjadi dua macam, yaitu sumber data primer dan sumber data sekunder. Data primer pada penelitian ini bersumberkan pada narasumber dan keyperson dari instansi atau pelaku terkait dalam kebijakan aglomerasi transportasi Jawa Tengah studi kasus Semarang - Bawen. Data sekunder, yaitu data yang diperoleh dalam bentuk angka-angka meliputi data jumlah angkutan umum pedesaan dan angkutan umum dalam kota dan data pendukung lainnya. Data yang digunakan dalam penelitian ini adalah data primer dan skunder. Data sekunder yang bersumberkan dari instansi terkait, yaitu Badan Pusat Statistik (BPS), Dinas Perhubungan Kabupaten Semarang yang berupa data jumlah angkutan umum pedesaan dan dalam kota. Adapun informan penelitian ini adalah orang-orang yang akan menikmati / orang-orang bertempat tinggal di sekitaran jalan raya yang akan dilalui bus rapid transit (BRT) koridor Semarang-Bawen di Kabupaten Semarang. Untuk mengumpulkan data digunakan teknik sebagai berikut:

Studi Kepustakaan, yaitu teknik pengumpulan data dengan mempelajari buku-buku, makalah, berita media sosial, jurnal penelitian dan bahan-bahan tertulis lainnya berhubungan dengan topik penelitian.
Wawancara, yaitu melakukan tanyajawab dengan pihak-pihak yang berhubungan dengan masalah penelitian yaitu respon masyarakat dengan adanya kebijakan aglomerasi transportasi massal Bus Rapid Transit (BRT) di Kabupaten Semarang, sehingga dapat dicapai tujuan penelitian.

Angket atau Kuesioner, Penelitian ini menggunakan angket atau kuesioner, daftar pertanyaannya dibuat secara terstruktur dengan bentuk pertanyaan pilihan berganda (multiple choice questions) dan pertanyaan terbuka (open question). Metode ini digunakan untuk memperoleh data tentang persepsi responden masyarakat.

Dokumentasi, yaitu perekaman bentuk suatu informsi baik itu dokumen, gambar, ataupun catatan-catatan terkait dengan permasalahan penelitian.

\section{Metode Analisis Data}

Metode analisis data yang digunakan untuk mengolah data yang diperoleh pada saat melakukan penelitian, sehingga akan didapatkan suatu kesimpulan tentang keadaan yang sebenarnya dari objek yang diteliti. Metode analisis yang digunakan dalam penelitian ini adalah Analisis Deskriptif Persentase. Sebelum melakukan analisis data penelitian harus memenuhi persyaratan valid dan reliabel.

Selanjutnya dalam memberikan interpretasi terhadap koefisien korelasi, Masrun (dalam Sugiono, 2009: 134) menyatakan bahwa item yang mempunyai korelasi positif dengan skor total serta korelasi yang tinggi, menunjukkan bahwa item tersebut mempunyai validitas yang tinggi pula 
Uji validitas tersebut menggunakan program SPSS versi 23.

\section{HASIL DAN PEMBAHASAN}

Penelitian ini dilakukan dengan mengambil tempat di daerah Kabupaten Semarang, yang rencana Pemerintah Jawa Tengah dilaksanakan pertama di koridor 1 yang berute atau trayek Kabupaten Semarang (Bawen) - Kota Semarang (Tawang). Pengambilan data pertama dilakukan dengan melakukan pengambilan responden sebanyak 15 orang, untuk melakukan suatu uji validitas dan reabilitas pada kuesioner. Kemudian pengambilan data kedua dengan menggunakan kuesioner dilakukan pada bulan Maret 2017 dengan 100 responden. Analisis dilakukan dengan pengujian deskriptif presentase. Sebanyak 55\% hasil keseluruhan jawaban para responden masih banyak angkutan umum angkot/bus yang selalu ngetem atau berhenti mencari penumpang sangat lama dan kadang juga berjalan sangat lambat, masyarkat sangat membutuhkan transportasi yang lebih on time, nyaman dan aman.

Sebagian besar responden yang diteliti memiliki kendaraan pribadi, sebanyak 80\%. Tanggapan responden mengenai pilihan akan adanya Bus Rapid Transit (BRT) menjawab setuju sebanyak 54\% untuk naik Bus Rapid Transit (BRT). Namum, beberapa responden memberi suatu alasan untuk Bus Rapid Transit (BRT) yang akan di lakukan untuk bisa diberikan jalur khusus agar lebih cepat dan tidak jadi satu dengan kendaraan pribadi di jalan raya. Kemudian responden sebanyak 52\% responden tidak mengetahui rute Bus Rapid
Transit (BRT) yang akan di luncurkan pertama sebagai transportasi aglomerasi di Kabupaten Semarang. Responden dengan jumlah 73\% menyatakan bahwa setuju dengan adanya pembedaan tarif naik Bus Rapid Transit (BRT). Sebanyak $75 \%$ juga setuju dengan adanya rencana tarif umum sebesar Rp. 5.000,00 dan tarif pelajar sebesar Rp. 2.00o,oo. selain itu, sebanyak 88 orang atau $88 \%$ menjawab setuju tentang tarif Bus Rapid Transit (BRT) lebih murah dibandingkan tarif angkutan umum.

Sebanyak 55\% hasil keseluruhan jawaban para responden masih banyak angkutan umum angkot/bus yang selalu ngetem atau berhenti mencari penumpang sangat lama dan kadang juga berjalan sangat lambat, masyarkat sangat membutuhkan transportasi yang lebih on time, nyaman dan aman.

Sebagian besar responden yang diteliti memiliki kendaraan pribadi, sebanyak 80\%. Tanggapan responden mengenai pilihan akan adanya Bus Rapid Transit (BRT) menjawab setuju sebanyak 54\% untuk naik Bus Rapid Transit (BRT). Namum, beberapa responden memberi suatu alasan untuk Bus Rapid Transit (BRT) yang akan di lakukan untuk bisa diberikan jalur khusus agar lebih cepat dan tidak jadi satu dengan kendaraan pribadi di jalan raya.

Kemudian responden sebanyak $52 \%$ responden tidak mengetahui rute Bus Rapid Transit (BRT) yang akan di luncurkan pertama sebagai transportasi aglomerasi di Kabupaten Semarang. Responden dengan jumlah 73\% menyatakan bahwa setuju dengan adanya pembedaan tarif naik Bus Rapid Transit (BRT). Sebanyak $75 \%$ juga setuju dengan adanya 
rencana tarif umum sebesar Rp. 5.000,oo dan tarif pelajar sebesar Rp. 2.00o,oo. selain itu, sebanyak 88 orang atau $88 \%$ menjawab setuju tentang tarif Bus Rapid Transit (BRT) lebih murah dibandingkan tarif angkutan umum.

\section{KESIMPULAN}

Berdasarkan hasil penelitian dan pembahasan mengenai analisis respon masyarakat terhadap kebijakan aglomerasi transportasi angkutan massal Bus Rapid Transit (BRT) di Kabupaten Semarang menunjukan bahwa respon masyarakat terhadap adanya kebijakan aglomerasi transportasi angkutan massal Bus Rapid Transit (BRT) di Kabupaten Semarang dilihat sangat setuju dan sangat antusias dengan akan adanya suatu kebijakan aglomerasi transportasi massal yang terintegrasi dengan kenyamanan, keaman dan kemurahannya. Namun masyarakat masih lebih minat untuk memilih kendaraan pribadi ketimbang naik angkutan Bus Rapid Transit (BRT). Harapan masyarakat setempat mengenai kebijakan aglomerasi transportasi angkutan massal Bus Rapid Transit (BRT) di Kabupaten Semarang yaitu semoga cepat terlaksana dengan adanyanya kebijakan aglomerasi transportasi angkutan berbasis Bus Rapid Transit (BRT) di Kabupaten Semarang yang terintegrasi dengan Kota Semarang. Karena dengan adanya Bus Rapid Transit (BRT) sangat membantu para masyarakat dengan transportasi yang murah, nyama, dan lebih aman. Selain itu bagi Pemerintah Jawa Tengah disarankan untuk segera melaksanakan Bus Rapid Transit (BRT) di Kabupaten Semarang yang akan terintrasi dengan Kota Semarang tersebut. Pemerintah juga mengevaluasi letak shelter yang memakan hak pengguna jalan kaki. Penambahan shelter Bus Rapid Transit (BRT) dan juga perawatan shelter yang mulai tidak terawat. Bagi masyarakat dengan akan adanya kebijakan transportasi angkutan massal Bus Rapid Transit (BRT) di Kabupaten Semarang ini agar bisa beralih dari kendaraan pribadi ke angkutan umum. Karena dengan menggunakan angkutan umum dapat mengurangi kemacetan dan kecelakaan, serta masyarakat juga ikut merawat barang fasilitas umum pemerintah.

\section{DAFTAR PUSTAKA}

Adisasmita, Rahardjo. (2010). Dasar-dasar Ekonomi Transportasi. Edisi pertama Mei 2010. Graha Ilmu, Yogyakarta.

Anggraeni, Ratna Dewi. (2009). Preferensi Pilihan Moda Dengan Kajian Intermodality pada Pergerakan Penumpang Angkutan Umum Jurusan BandungJakarta (Studi Kasus: Moda Kereta Api dan Travel). Master Theses Institut. Teknologi Bandung (ITB).

Arikunto, Suharsimi. 1996. Prosedur Penelitian: Suatu Pendekatan Pratik. Jakarta. Rineka Cipta.

Chairunnisa, Yane. Rachmawati, Rini. 2012. Kajian Penyediaan dan Pemanfaatan Pelayanan Transportasi Publik di Kota Bekasi. Jurnal Bumi Indonesia Volume 1, Nomor 3, Tahun 2012. Fakultas Geografi, Universitas Gadjah Mada.

Departemen Perhubungan 2003. Keputusan Menteri Perhubungan No. KM 35 Tahun 2003 tentang Penyelenggaraan Angkutan Orang di Jalan dengan Kendaraan Umum. Jakarta: Direktorat Jenderal Perhubungan Darat.

Djogo, Tony. 2003. Kelembagaa dan Kebijakan dalam Pengembangan Agroforestri. Bogor: World Agroforestry Centre (ICRAF).

Haryono, Sigit. 2010 "Analisis Kualitas Pelayanan Angkutan Umum (Bus Kota) di Kota Yogyakarta”. Jurusan Ilmu Administrasi Bisnis, FISIP UPN Veteran, Yogyakarta.

Hasim, Indayani. 2013. Analisis Keterkaitan Transportasi Darat Dengan Pertumbuhan Ekonomi di Kabupaten Merauke Periode 2002-2011. Skripsi: Makassar. Fakultas Ekonomi dan Bisnis, Universitas Hasanuddin.

Ismaniar, Aisyah Rizqi. Prishardoyo, Bambang. 2017. Implementasi Kebijakan Tarif Angkutan Umum Jenis Mobil Penumpang Umum di Kota Semarang. Economics Development Analysis Journal 6 (1) 
Fakultas Ekonomi, Universitas Negeri Semarang (Unnes). Kurniawan, Aditya. 2013. Rancangan Bangunan Aplikasi Pemilihan Alat Transportasi Umum Kota Surabaya Menggunakan Metode Spanning Tree Pada Smartphone Android.undergaraduate thesis, STIKOM Surabaya.

Nasution, 1996, “Manajemen Transportasi”. Penerbit PT. Ghalia Indonesia, Jakarta.

Putri Pradina, Dinanti. Kerjasama Antara Daerah Dalam Penyediaan Transportasi Publik (Kajian Transportasi BRT Kota Semarang - Kab. Semarang). Skripsi: Semarang. Fakultas Ilmu Sosial dan Ilmu Politik Undip.

Raul, Syafruddin. Ahmad Faisal. A. 2013. Analisis Kinerja dan Pemerataan Angkutan Umum (Mikrolet) di Kota Makassar (Studi Kasus : Angkutan Umum Trayek A,C,G,J,S). Jurnal Konferensi Nasional Teknik Sipil 7 (KoNTekS 7). Universitas Sebelas Maret (UNS): Surakarta.

Rustian, dalam Septiana, Arum., R. Mulyo Hendarto. 2012. Analisis Ususlan Kebijakan Solusi Kemacetan Lalu-Lintas di Kawasan Tembalang Semarang. Journal Of Economics volume 1 no. 1 tahun 2012. Universitas Diponegoro.

Siregar. M. 1995. Kumpulan Tulisan Perencanaan Pembangunan Sistem Transportasi. Sekretariat Jenderal Depertemen Perhubungan R.I., Jakarta.

Sukirno, Sadono. 2005. Mikro Ekonomi Teori Pengantar. Edisi Ketiga, Raja Grafindo Persada, Jakarta.

Sugiyono. 2009. Metode Penelitian Kuantitatif, Kualitatif dan R \& D. Bandung: Penerbit Alfabeta.

Ulya, Aniqotul. 2013. Pengaruh Kualitas Pelayanan Inti dan Kualitas pelayanan Periferal Terhadap Kepuasan Konsumen Dalam Meningkat Minat Menggunakan Ulang. Skripsi: Semarang. Fakultas Ekonomi dan Bisnis. Universitas Negeri Dipenogoro.

Warpani, S.P. 2002. Pengelolaan Lalu Lintas dan Angkutan Jalan. Bandung: Penerbit ITB.
Wirasutama, Cokorda Putra. 2014. Analisis Kelayakan Finansial Angkutan Pariwisata di Provinsi Bali (Studi Kasus Pada PT. GD Bali Transport dan PT. Amanda Legian Tours. Skripsi. Program Pascasarjana, Universitas Udayana: Denpasar.

Wulandari, Indah Apriliana Sari. (2011). Pengembangan Model Penentuan Prioritas Perencanaan Transportasi Jangka Panjang Dengan Menggunakan Pendekatan Multi Criteria Decision Making (MCDM). QMM - Pasca Sarjana Teknik Industri. Institut Teknologi Sepuluh Nopember.

Trayek Diserobot, Sopir Angkudes Mogok. (2012). http://suaramerdeka.com/v1/index.php/read/ceta k/2012/o4/17/183511/Trayek-Diserobot-SopirAngkudes-Mogok. (Diakses pada 21 Maret 2015, pukul 23.20 WIB)

Visi dan Misi DINHUBKOMINFO PROVINSI JATENG. http://dinhubkominfo.jatengprov.go.id/?page_id= 10. (Diakses pada 25 April 2015, pukul 19.25 WIB).

Rencananya, 40 BRT (Bus Rapid Transit) Layani Semarang - $\quad$ Bawen. 2015. http://www.harian7.com/2015/o1/rencananya-40brt-bus-rapid-transit.html. (Diakses pada 4 Agustus 2015, pukul 17.15 WIB).

BRT Kurangi Kemacetan. 2014. http://www.jurnalasia.com/2014/05/21/brt-

kurangi-kemacetan/. (Diakses pada 6 Agustus 2015, pukul 17.30 WIB).

Layanan BRT Harus Ditingkatkan. 2014 http://www.koransindo.com/read/921319/151/layanan-brt-harusditingkatkan-1415358418. (Diakses pada 25 Agustus 2015. Pukul 21.30 WIB).

Jateng, Tribun. (2015). http://jateng.tribunnews.com/2014/12/26/dishubk ominfo-prediksi-penggunaan-angkutan-umumturun-2422-persen. (Diakses pada 3 September 2015.pukul

20.25

WIB) 


\section{LAMPIRAN}

Tabel 1. Hasil Persentase Pertanyaan Responden

\begin{tabular}{|c|c|c|c|}
\hline No & Pertanyaan & Ya & Tidak \\
\hline 1 & Memiliki kendaraan pribadi & $80 \%$ & $20 \%$ \\
\hline 2 & Kemudahan memperoleh transportasi angkot dan bus & $85 \%$ & $15 \%$ \\
\hline 3 & Mengenai angkot/bus dapat mempercepat waktu & $45 \%$ & $55 \%$ \\
\hline 4 & Akan adanya BRT di Kabupaten Semarang & $94 \%$ & $6 \%$ \\
\hline 5 & BRT di butuhkan di Kabupaten Semarang & $90 \%$ & $10 \%$ \\
\hline 6 & $\begin{array}{l}\text { Dengan adanya BRT, masyarakat akan lebih menggunakan } \\
\text { BRT dibandingkan kendaraan pribadi }\end{array}$ & $46 \%$ & $54 \%$ \\
\hline 7 & BRT berdampak pada kemudaan memperoleh transportasi & $92 \%$ & $8 \%$ \\
\hline 8 & tentang mengetahui rute BRT di Kabupaten Semarang & $48 \%$ & $52 \%$ \\
\hline 9 & $\begin{array}{l}\text { mengenai sudah mendapatkan sosialisasi tentang akan } \\
\text { adanya Bus Rapid Transit BRT di Kabupaten Semarang }\end{array}$ & $25 \%$ & $75 \%$ \\
\hline 10 & $\begin{array}{l}\text { mengenai perlu atau tidak dengan adanya pembedaan tarif } \\
\text { Bus Rapid Transit (BRT) }\end{array}$ & $73 \%$ & $27 \%$ \\
\hline 11 & $\begin{array}{l}\text { mengenai pembelian tiket Bus Rapid Transit (BRT) dapat } \\
\text { dilakukan di shelter (tempat pemberhentian khusus BRT) } \\
\text { atau di petugas BRT }\end{array}$ & $86 \%$ & $14 \%$ \\
\hline 12 & $\begin{array}{l}\text { mengenai rencana tarif yang akan dikenakan oleh pengguna } \\
\text { Bus Rapid Transit (BRT) sebesar Rp. 5.ooo,- (umum) dan } \\
\text { Pelajar Rp. 2.ooo,- }\end{array}$ & $75 \%$ & $25 \%$ \\
\hline 13 & $\begin{array}{l}\text { tentang tarif Bus Rapid Transit (BRT) lebih murah } \\
\text { dibandingkan tarif angkutan umum angkot dan bus }\end{array}$ & $88 \%$ & $12 \%$ \\
\hline 14 & $\begin{array}{l}\text { akan adanya keberadaan Bus Rapid Transit (BRT) dapat } \\
\text { mempersingkat waktu perjalanan }\end{array}$ & $65 \%$ & $35 \%$ \\
\hline 15 & $\begin{array}{l}\text { sistem pembayaran sekali pada saat pemberangkatan } \\
\text { mempermudah dalam pembayaran tarif Bus Rapid Transit } \\
\text { (BRT) }\end{array}$ & $99 \%$ & $1 \%$ \\
\hline 16 & $\begin{array}{l}\text { adanya kebijakan pembedaan tempat duduk (Laki-laki dan } \\
\text { Perempuan) untuk memberikan rasa aman dan nyaman }\end{array}$ & $93 \%$ & $7 \%$ \\
\hline 17 & $\begin{array}{l}\text { adanya pemberian tempat duduk khusus bagi penyadang } \\
\text { cacat/difabel pada Bus Rapid Transit (BRT) }\end{array}$ & $93 \%$ & $7 \%$ \\
\hline 18 & $\begin{array}{l}\text { akan beroperasinya armada Bus Rapid Transit (BRT) dapat } \\
\text { mengurangi angka kemacetan }\end{array}$ & $70 \%$ & $30 \%$ \\
\hline 19 & $\begin{array}{l}\text { dengan adanya pemberhentian shelter yang di sediakan } \\
\text { sudah cukup aman dari risiko kecelakaan }\end{array}$ & $77 \%$ & $23 \%$ \\
\hline
\end{tabular}

